\title{
THE OUTCOME OF HEIGHT IN A COHORT OF CHILDREN WITH CONGENITAL ADRENAL HYPERPLASIA: A PRELIMINARY REPORT FROM
} SRI LANKA

\author{
Athapathu AS ${ }^{1}$, Jayawardena BAAJ ${ }^{1}$, Hewage WA' ${ }^{1}$, de Silva $\mathrm{KSH}^{1,2}$ \\ ${ }^{1}$ Department of Paediatrics, Faculty of Medicine, University of Colombo, ${ }^{2}$ Lady Ridgeway Hospital, Colombo.
}

\section{ABSTRACT}

Introduction: Adequate replacement therapy with hydrocortisone is essential in congenital adrenal hyperplasia to achieve satisfactory growth in height and age appropriate skeletal maturity. Our objectives were to assess the heights of a cohort of children with $\mathrm{CAH}$ in relation to the standard dosage of hydrocortisone and duration of therapy.

Method: Clinical data of 22 patients followed up at the University Paediatric Unit at the Lady Ridgeway Hospital, Colombo were documented using an interviewer administered questionnaire. Their heights after completion of 1, 4 and 7 years of therapy were recorded with the corresponding dose of hydrocortisone and bone age. Height standard deviation scores (SDS) were calculated for each patient and the mean (SD) values in the 3 groups of patients.

Results: Fifteen (68.2\%) were girls and $20(90.9 \%)$ had the salt-wasting form of CAH. After completion of 1,4 and 7 years of treatment, the height SDS ranged from (-3.16 to 2.12), (-2.9 to 2.92$)$ and (-1.65 to 1.74) with mean (SD) of -0.59 (1.39), -0.2 (1.37) and $-0.08(0.98)$ respectively. The corresponding mean (SD) hydrocortisone doses ( $\mathrm{mg} / \mathrm{m}^{2} /$ day) were $12.19(4.62), 11.53(3.61)$ and 11.01 (2.77). The bone age advancement reduced over time. Nineteen out of $22(86.4 \%)$ and all 13 were in the normal height SDS range (-2SD to $+2 \mathrm{SD})$ after 1 and 7 years of treatment respectively.

Conclusions: Hydrocortisone therapy in the recommended dosage in CAH is associated with a satisfactory achievement of height.

\section{INTRODUCTION}

Congenital adrenal hyperplasia $(\mathrm{CAH})$ is a rare genetic disorder associated with defective adrenal steroid biosynthesis and this is commonly due to deficiency of 21 hydroxylase enzyme. It is inherited as an autosomal recessive disorder with a worldwide incidence of 1:10,000 to 1: 20,000 births (1). An estimated prevalence of 0.181 : 10,000 has been reported from Sri Lanka in 2013 (2). The enzyme 21 hydroxylase deficiency leads to two types of clinical syndromes: saltwasting (SW) and non-salt-wasting or simple virilising (SV) forms, the former being the commoner manifestation (3).

Optimum hydrocortisone replacement is the key to the satisfactory auxological outcome in children with
CAH. Lifelong steroid replacement therapy with a glucocorticoid dosage that is sufficient enough to suppress ACTH secretion and hence the excessive androgen production is essential to suppress the virilization of these patients. Inadequate suppression of androgens causes an increase in the height velocity and advancement of the bone age, leading to a taller child (3) However, the early bone maturation and epiphyseal closure will ultimately produce a short adult with virilization. Adequate supper-ssion of the raised androgens during childhood can ensure normal growth velocity and skeletal maturation and normal adult height. The dose of hydrocortisone has to be carefully titrated and closely monitored against the radiological and biochemical investigations for these children with $\mathrm{CAH}$ to achieve their biological potential in height.
The hydr-ocortisone dose of 10 to $15 \mathrm{mg} / \mathrm{m}^{2} /$ day is recommended in the management of $\mathrm{CAH}(1,4)$. Adequate steroid replacement has to be ensured by the periodical assessment of clinical parameters such as growth and skeletal maturity by measuring the height and the bone age of the individual patients and by appropriate dose adjustments (3, 5). In addition to the glucocorticoids, mineralocorticoids replacement is also needed in the salt-wasting forms of $\mathrm{CAH}$.

In patients with $\mathrm{CAH}$, insufficient glucocorticoid replacement therapy leads to increased androgen production causing initial rapid growth at the expense of final adult height. In contrast, over replacement may lead to a delay in skeletal maturation and short stature (3). The objective of this study was to assess the outcome 
of height in children with $\mathrm{CAH}$ relative to the duration and standard dosage of hydr-ocortisone replacement therapy.

\section{METHOD}

From the cohort of patients with $\mathrm{CAH}$ followed up at the University Paediatric Unit at the Lady Ridgeway Hospital, those identified clinically and biochemically as having the saltwasting (SW) and non-salt-wasting (simple virilizing: SV) forms of 21 hydroxylase deficiency $\mathrm{CAH}$ were initially selected for the study. From this group of patients, the children who had been followed up for more than one year in the ward were invited to participate in the study. An interviewer administered questionnaire was used to record data collected by perusing the clinic records maintained by one of the investigators and where necessary from parents.

The patient's heights were measured using a wall-mounted stadiometer and the inter-observer variations of the height measurements were minimized by taking measurements by a single investigator. Oral hydrocortisone tablets were used as the standard treatment and the standard recommended dosage of 10 $15 \mathrm{mg} / \mathrm{m} 2 /$ day, given twice or three times a day in divided doses. The hydrocortisone dosage of the individual patient was periodically titrated against clinical (height and the bone age) and biochemical (serum 17 hydroxyprogesterone and Dehydroepiandrosterone levels). To realize the objectives of the study, the study cohort was divided into 3 groups based on the duration of therapy. The time periods were taken as after completion of one, four and seven years of treatment. The heights of the patients in these 3 groups were recorded with the corresponding hydrocortisone dose and bone age and the height standard deviation scores (SDS) were calculated for each patient and the mean (SD) values for the hydrocortisone dose and height SDS were recorded. Data was analyzed using SPSS 21 statistical software. The ethics review

Table 1: Province of residence of the patients $(n=22)$

Province

Number of patients (\%)

\begin{tabular}{lc}
\hline Western & $11(50)$ \\
Central & $03(13.6)$ \\
North Western & $04(18.2)$ \\
North Central & $02(9.1)$ \\
Sabaragamuwa & $02(9.1)$ \\
\hline
\end{tabular}

Table 2: Clinical features at presentation $(n=22)$

Clinical feature

Number of patients (\%)

\begin{tabular}{lc}
\hline Dehydration & $11(50)$ \\
Vomiting & $06(27.3)$ \\
Significant weight loss & $07(31.8)$ \\
\hline Increased pigmentation & $16(72.7)$ \\
Ambiguous genitalia & $15(68.2)$ \\
\hline
\end{tabular}

committee of the Faculty of Medicine, University of Colombo, approved the study.

\section{RESULTS}

Based on the selected criteria, twentytwo patients were invited and recruited after obtaining informed consent to participate in the study. All 22 patients had been followed up for 4 years and their outcome was analyzed at the completion of one and four years of therapy. There were thirteen patients who had completed 7 years of therapy and the analysis in this group was done at the completion of 7 years of therapy.

Duration of treatment in the remaining 9 children ranged from $>4$ to $<7$ years.

There were $15(68.2 \%)$ girls and 7 $(31.8 \%)$ boys. Their ages at the time of study ranged from 4.16 years to 16.0 years with a mean (SD) of 8.85 (3.168) years. Twenty $(90.9 \%)$ were products of nonconsanguineous unions. The majority of them (11; $50 \%$ were from the Western Province (Table 1).

Twenty children $(90.9 \%)$ had the salt- wasting form (SW) of the condition. The age at initial presentation to our ward ranged from 1 day to 120 days with a mean (SD) of 16.28 (30.48) days. The commonest presenting features were hyperpigmentation seen in 16 and ambiguous genitalia seen in all 15 baby girls (Table 2).

The height standard deviation scores (SDS) after completion of 1, 4 and 7 years of treatment, ranged from (3.16 to 2.12$),(-2.9$ to 2.92$)$ and (-1.65 to 1.74 ) with the mean (SD) values of -0.59 (1.39), -0.2 (1.37) and -0.08 (0.98) respectively (Table 3$)$. The corresponding mean (SD) hydrocortisone doses $\left(\mathrm{mg} / \mathrm{m}^{2} /\right.$ day $)$ were 12.19 (4.62), 11.53 (3.61) and 11.01 (2.77). After one year of therapy 19 out of $22(86.4 \%)$ were in the normal height SDS range (-2SD to $+2 \mathrm{SD})$ and at 7 years of follow-up, all 13 patients who had completed 7 years of therapy, were in the normal height SDS range. The bone age advancement reduced over time as shown by the decreasing bone age:chronological age ratio $(\mathrm{BA} / \mathrm{CA}$ ratio) - Table 3. The mid-parental heights were not taken into consideration as this is an interim report of the short-term outcome of height and not the final adult height. 
Table 3: Clinical, pharmacological and radiological aspects of the study population at different points

Characteristics of the study

Duration of therapy

population

\begin{tabular}{|c|c|c|c|}
\hline & 1 year & 4 years & 7 years \\
\hline Number of patients & 22 & 22 & 13 \\
\hline Height SDS range Mean (SD) & $\begin{array}{c}-3.16 \text { to } 2.12 \\
0.59(1.39)\end{array}$ & $\begin{array}{l}-2.9 \text { to } 2.92 \\
-0.2(1.37)\end{array}$ & $\begin{array}{l}-1.65 \text { to } 1.74 \\
-0.08(0.98)\end{array}$ \\
\hline Hydrocortisone dose $\mathrm{mg} / \mathrm{m}^{2} /$ day Mean (SD) & $12.19(4.62)$ & $11.53(3.61)$ & $11.01(2.77)$ \\
\hline Mean BA/CA & NA & 1.47 & 1.37 \\
\hline Number $(\%)$ in normal height range (-2SD to $+2 \mathrm{SD})$ & $19 / 22(86.4)$ & $19 / 22(86.4)$ & $13 / 13(100)$ \\
\hline
\end{tabular}

$\mathrm{BA} / \mathrm{CA}-$ Bone age / chronological age

NA - Not available

\section{DISCUSSION}

Congenital adrenal hyperplasia is a rare genetic disorder, if not treated properly (both under treatment and over-treatment), could lead to short stature and virilization. Properly monitored hydrocortisone treatment can replenish the cortisol requirement and suppresses the inappropriate ACTH elevation enabling normal growth in patients with $\mathrm{CAH}$. This is the first report from Sri Lanka regarding the short-term outcome in heights in children with $\mathrm{CAH}$ where we have seen a satisfactory height gain with standard recommended hydrocortisone replacement.

The effects of glucocorticoid replacement and height outcomes in patients with $\mathrm{CAH}$ are variable and the studies have reported positive correlations, negative correlations and no associations with the treatment $(5,6,7)$. A multi-center study of Caucasian patients has demonstrated an impairment of growth up to 3 years of age in patients with salt-wasting $\mathrm{CAH}$, which normalized during later childhood. However, the final heights of these patients were less than the reference and individual target heights (5).

A reasonable number of studies have demonstrated the negative influence of steroid replacement on adult height of patients with $\mathrm{CAH}$. This negative influence on height attainment for genetic height potential has been reported in 2006 after 8.5 years of follow-up with a hydrocortisone dose of 17.64 (3.60) $\mathrm{mg} / \mathrm{m}^{2} /$ day for patients with classical CAH (8). A study from Turkey in 2009 has reported that $79.1 \%$ of patients with $\mathrm{CAH}$ treated with an average daily hydrocortisone dose of 19.7 (2.9) $\mathrm{mg} / \mathrm{m}^{2}$ for 14.2 (3.1) years to have an adult height below the target height and $54.2 \%$ of them to be overweight or obese. These studies highlighted the ne-gative influence of over treatment and the importance of using the lowest possible dose of hydrocortisone in the treatment of CAH (7). Our results indicated a satisfactory achievement of height in almost all the children who received the recommended dose of hydrocortisone where nineteen $(86.4 \%)$ children had reached the normal height after one year of therapy, while all 13 patients $(100 \%)$ had reached the expected height for age after 7 years of treatment.
There is evidence to suggest that the type of $\mathrm{CAH}$ has an effect on the final height outcome. A study comparing the final heights of patients with salt-wasting (SW) and non-salt wasting (simple virilising: SV) $\mathrm{CAH}$ has reported the final height to be less than the target height in the SV compared to the SW form of CAH. Delayed diagnosis and the resultant advancement of bone age were attributed to be the possible reasons for these findings (9). In our cohort, we had 2 patients with simple virilising $\mathrm{CAH}$, aged 14 yearrs and 7 months and 13 years and 9 months at the time of the study. Their heights and height SDS were $154 \mathrm{~cm}(-0.67)$ and $150.8 \mathrm{~cm}(-$ 0.46) respectively which was a satisfactory outcome probably due to the early diagnosis and appropriate hydrocortisone replacement during their course of the disease.

Although the short term height deviations are acceptable, the final adult height in relation to the target height is yet to be determined. However, it is important that these patients are followed up with close monitoring of height and the skeletal maturity with hydrocortisone dose adjustments when indicated, through puberty until the final adult height is reached. 


\section{REFERENCES}

1. Speiser PW, Azziz R, Baskin LS, Hensle TW, Merke DP, Miller WL et al. Congenital Adrenal Hyperplasia Due to Steroid 21Hydroxylase Deficiency: An Endocrine Society Clinical Practice Guideline. Journal of Clinical Endocrinology and Metabolism. 2010; 95(9): 4133-4160.

2. Jayasena A, Gunawardena N, de Silva S. A descriptive analysis and prevalence of congenital adrenal hyperplasia in Sri Lankan children. Endocrine Abstracts (2013). Proceedings of the 41 st Meeting of the BSPED, UK, November 2013. DOI:10.1530/endoabs.33.P2

3. Dauber A, Kellogg M, Majzoub JA. Monitoring of Therapy in Congenital Adrenal Hyperplasia. Clinical Chemistry. 2010; 56(8): 1245-1251.

4. Consensus statement on 21hydroxylase deficiency from the Lawson Wilkins Pediatric Endocrine Society and the European Society for Paediatric Endocrinology. Journal of Clinical Endocrinology and Metabolism. 2002; 87: 4048-4053.

5. Hargitai G, Solyom J, Battelino T, Lebl J, Kovacs J, Frisch H et al. Growth Patterns and Final Height in Congenital Adrenal Hyperplasia due to Classical 21-Hydroxylase Deficiency. Results of a Multicenter Study. Hormone Research. 2001; 55: 161-171.

6. Sarafoglou K, Addo OY, Turcotte L, Kyllo J, Lteif AN, Himes JH et al. Impact of hydrocortisone on adult height in CAH. Journal of Pediatrics. 2014; 164(5): 1141 1146.

7. Aycan Z, Akbuga S, Centikaya E, Ocal G, Berberoglu M, Adryaman $P$ et al. Final height of patients with classical CAH. Turkish Journal of Pediatrics. 2009; 51: 539-544.

8. Aycan Z, Ocal G, Berberoglu M, Cetinkaya E, Adiyaman $P$, Evliyaoglu O. Experience with long-term glucocorticoid treatment in congenital adrenal hyper-plasia: growth pattern compared with genetic height potential. Journal of Pediatric Endocrinology and Metabolism. 2006; 19(3): 245-251.
9. Manoli I, Kanaka-Gantenbein Ch, Voutetakis A, Maniati-Christidi $\mathrm{M}$, Dacou-Voutet-akis C. Early growth, pubertal development, body mass index and final height of patients with congenital adr-enal hyperplasia: factors in-fluencing outcome. Clinical Endocrinology. 2002; 57(5): 669-676. 